\title{
Isolate Specificity and Polygenic Inheritance of Resistance in Barley to Diverse Heterologous Puccinia striiformis Isolates
}

\author{
R. Haghdoust, D. Singh, D. P. Garnica, R. F. Park, and P. M. Dracatos ${ }^{\dagger}$
}

First, second, fourth, and fifth authors: The University of Sydney, Plant Breeding Institute, Cobbitty, Private Bag 4011, Narellan, NSW, 2567, Australia; and second author: CSIRO Plant Industries, GPO Box 1600, Canberra, ACT, 2601, Australia. Accepted for publication 11 December 2017.

\begin{abstract}
Barley is a host to Puccinia striiformis f. sp. hordei, and is an intermediate or near nonhost to the formae speciales adapted to wheat (P. striiformis f. sp. tritici) and to barley grass (P. striiformis f. sp. pseudohordei). The genetic basis of resistance to these forms of $P$. striiformis is not well understood. Accordingly, a recombinant inbred line (RIL) population was developed using a P. striiformis-susceptible accession (Biosaline-19) and the immune cultivar Pompadour. We investigated the genetic basis of resistance to four diverse $P$. striiformis isolates (P. striiformis $\mathrm{f}$. sp. pseudohordei, and P. striiformis f. sp. tritici pathotypes 104 E137 A-, 134 E16 A+, and 64 E0 A-). and determined that the immunity in Pompadour at the seedling stage to the different $P$. striiformis isolates was due to quantitative trait loci (QTL) on chromosomes $1 \mathrm{H}, 3 \mathrm{H}, 5 \mathrm{H}$, and $7 \mathrm{H}$ with both overlapping and distinct specificities. Further histological analysis confirmed the presence of isolate specificity. The RILs were also assessed in

the field for resistance to $P$. striiformis $\mathrm{f}$. sp. pseudo-hordei, $P$. striiformis f. sp. hordei, and the leaf rust pathogen ( $P$. hordei) to identify pleiotropic QTL loci effective at the adult plant stage and determine whether the leaf rust resistance in Pompadour (Rph20) was also effective to $P$. striiformis. RILs that were seedling susceptible to P. striiformis f. sp. pseudo-hordei were resistant in the field, implicating the involvement of adult plant resistance (APR). Additional QTLs were identified on chromosome $7 \mathrm{H}$ at the same genetic position as Rph23 (APR to leaf rust), suggesting either pleiotropic resistance or the presence of a stripe rust resistance gene closely linked to or allelic with Rph23. Unlike many pleiotropic APR genes identified and isolated in wheat, our data suggest that the Rph20 locus does not confer resistance to the $P$. striiformis isolates used in this study ( $P$. striiformis f. sp. hordei $\left[\chi^{2}\right.$ (independence) $\left.=2.47 P>0.12\right]$ and $P$. striiformis f. sp. pseudo-hordei $\left[\chi^{2}\right.$ (independence) $\left.=0.42 P>0.60\right]$ ).
\end{abstract}

Puccinia striiformis var. striiformis Westend is a basidiomycete fungus belonging to the order Uredinales, which causes stripe rust disease on some cereal crops and grasses. Stripe rust occurs globally in most cereal growing areas, especially in mountainous areas and in cooler climates, where it dramatically reduces the yield and quality of both grain and forage crops. The wheat stripe rust pathogen $P$. striiformis $\mathrm{f}$. sp. tritici is arguably the most important cereal rust pathogen globally based on the frequency of epidemics on wheat crops worldwide (Chen et al. 2002). While not as widespread, the barley-adapted $P$. striiformis f. sp. hordei causes yield losses in barley growing areas in the United States, South America, Europe, and the subcontinent. While not present in Australia, P. striiformis $\mathrm{f}$. sp. hordei is regarded as a serious exotic threat. Two incursions of exotic $P$. striiformis f. sp. tritici isolates have been documented in Australia, each with distinct virulence spectra and believed to have originated from France and the United States in 1979 and 2002, respectively (Wellings 2007; Wellings et al. 2003). Wellings et al. (2000) reported a variant of $P$. striiformis (f. sp. pseudo-hordei) adapted to wild Hordeum spp. (barley grass yellow rust [BGYR]) as a further exotic incursion of $P$. striiformis. Annual assessments of Australian barley germplasm determined that $10 \%$ of barley

${ }^{\dagger}$ Corresponding author: P. M. Dracatos; E-mail: peter.dracatos@sydney.edu.au

Funding: Funding was provided by the Grains Research and Development Corporation and the Coffey family.

Author contributions. R.H. and P.D. drafted the manuscript and R.H. performed the research. P.D., D.S., and R.F.P. planned the study, supervised the analysis, and revised the manuscript. D.P.G. performed the histology and reviewed the manuscript.

*The $\boldsymbol{e}$-Xtra logo stands for "electronic extra" and indicates that four supplementary tables are published online.

(c) 2018 The American Phytopathological Society cultivars were susceptible to BGYR. Similar to $P$. striiformis f. sp. hordei, P. striiformis f. sp. pseudo-hordei is avirulent on most of the wheat stripe rust differentials, with the exception of Chinese 166 (Wellings et al. 2000).

Breeding for resistance to stripe rust is widely recognized as the most economically and environmentally efficient method of control, however few resistances have proven durable due to rapidly evolving prevailing pathogen populations. Although many stripe rust resistance genes have been identified in wheat ( 75 cataloged $\mathrm{Yr}$ loci [Herrera-Foessel et al. 2011, 2014; Randhawa et al. 2014]), comparatively less is known about the mechanisms and genetic basis of resistance to $P$. striiformis in barley. In barley four resistance genes have been formally cataloged (rps1.a, rpsl.b, rps1.c, rps 2 , rps3, and Rps4) although numerous resistances have been identified and given a temporary designation (i.e., rpsEm1, rpsEm2, rpsAst, rpsHil, rpsHi2, rpsVa1, rpsVa2, rpsTr1, and rpsTr2)(Chen and Line 2002). Furthermore, in wheat two non-specific pleiotropic adult plant resistance (APR) genes including Lr34/Yr18/Sr57/Pm38 (Krattinger et al. 2009) and Lr67/Yr46/Sr55/Pm46 (Moore et al. 2015) that have been recently cloned confer resistance to all variants of the three rust pathogens that affect wheat. Three APR genes, $R p h 20$ (Hickey et al. 2011), Rph23 (Singh et al. 2015), and most recently Rph 24 (Ziems et al. 2017), have been formally designated in barley against leaf rust. Of these, only $R p h 20$ has been reported to be tentatively associated with resistance to powdery mildew (Blumeria graminis) (Hickey et al. 2012). Studies are required to determine the specificity of resistance in barley to different isolates and formae speciales of $P$. striiformis and ideally to identify genes that are pleiotropic (effective to multiple isolates and pathogens), which are likely to provide more durable control.

Nonhost resistance refers to a situation where an entire plant species is resistant to all genotypes of a particular plant pathogen (Heath 2000, 2002). Many plant pathogens, including the rust fungi are highly host specific, which for some Puccinia species has led 
to the evolution of forms within species that are specialized to a particular host, viz. "formae speciales" (f. sp.) (Eriksson 1894). Formae speciales are morphologically identical and induce very similar disease symptoms, yet each has a specific and distinct host range. In the case of $P$. striiformis, two economically significant formae speciales exist ( $P$. striiformis f. sp. tritici and P. striiformis f. sp. hordei); both are specialized to closely related hosts wheat and barley, respectively, within the Triticeae subtribe. Previous studies have established that in rare cases some wheat genotypes can be infected by $P$. striiformis f. sp. hordei and some barley genotypes can be infected by P. striiformis f. sp. tritici (Niks et al. 2013; Pahalawatta and Chen 2005b, a). This situation has been referred to as near-nonhost or marginal host resistance (Niks and Marcel 2009). Numerous studies in barley have determined that it is a near nonhost to many other heterologous Puccinia rust pathogens including: $P$. triticina, $P$. graminis f. spp. lolii and avenae, and P. striiformis f. spp. tritici and bromii (Atienza et al. 2004; Dracatos et al. 2014; Jafary et al. 2006).

The identification of rare susceptibility in some cereal accessions to heterologous Puccinia taxa has permitted inheritance studies with the aim to understand the genetic basis and mechanisms of resistance to heterologous pathogens. Such resistant genes can then be transferred between cereal crops as an alternative method of disease control. We previously identified a barley genotype that was susceptible to $P$. striiformis $\mathrm{f}$. sp. tritici and $P$. striiformis f. sp. pseudo-hordei (Biosaline-19 [B-19]) at all growth stages and developed a recombinant inbred line (RIL) population by crossing B-19 with Pompadour (has been found to be resistant to stripe rust and carries APR to leaf rust [P. hordei] due to gene Rph20) (Golegaonkar 2007). The population was tested with four diverse $P$. striiformis isolates ( $P$. striiformis f. sp. pseudo-hordei and P. striiformis f. sp. tritici pathotypes [104 E137 A-, $134 \mathrm{E} 16 \mathrm{~A}+$, and 64 E0 A-], P. striiformis f. sp. hordei [race 24], and P. hordei) with the aim to determine (i) the genetic basis and overlap of resistance specificity in barley to genetically diverse isolates of $P$. striiformis; and (ii) the effectiveness of leaf rust APR Rph20 to P. striiformis (pleiotropic effect).

\section{MATERIALS AND METHODS}

Plant materials. Genotype Biosaline-19 (B-19) was identified during routine field assessments in 2008 as being susceptible to the heterologous wheat and barley grass stripe rust pathogens (P. striiformis f. sp. tritici and P. striiformis f. sp. pseudo-hordei), respectively. Further phenotypic assessment also determined that B-19 was susceptible to $P$. striiformis f. sp. tritici and $P$. striiformis $\mathrm{f}$. sp. pseudo-hordei at the seedling stage in the greenhouse, making it suitable as a parent in developing populations for genetic studies of resistance to $P$. striiformis in barley. B-19 was crossed with Pompadour, a two-rowed barley genotype with high levels of stripe rust and leaf rust resistance (due to APR gene Rph20) to develop an
$\mathrm{F}_{9}$ RIL population (P/B-19; 98 lines). This population was used with the aim of mapping quantitative trait loci (QTL) for resistance to diverse $P$. striiformis isolates and determining the involvement of $R p h 20$ in resistance to $P$. striiformis.

Pathogen isolates. All single-pustule derived rust pathogen isolates used in this study are described in Table 1. With the exception of $P$. striiformis f. sp. hordei (race 24), all isolates are maintained under liquid nitrogen at the Plant Breeding Institute, University of Sydney, Australia. In the greenhouse, three $P$. striiformis f. sp. tritici isolates and one $P$. striiformis f. sp. pseudo-hordei isolate were used to infect the Pompadour/Biosaline-19 (P/B-19) mapping population. All three $P$. striiformis $\mathrm{f}$. sp. tritici isolates were previously well characterized for their virulence/avirulence spectra on the Australian P. striiformis f. sp. tritici differential set, two of which (pathotypes 104 E137 A- and 134 E16 A+) represent the founding isolates of two separate exotic incursion events into Australia (Wellings 2007). Pathotype 64 E0 A-is a relatively avirulent $P$. striiformis f. sp. tritici pathotype with virulence only on $Y r 4$. The standard $P$. striiformis f. sp. pseudo-hordei isolate 981549 was used at both seedling and adult plant stages for greenhouse and field inoculations, respectively. $P$. hordei pathotype $5457 \mathrm{P}+$ and $P$. striiformis f. sp. hordei race 24 were used for field testing for leaf rust and stripe rust resistance respectively. Leaf rust field trials were conducted at Cobbitty, University of Sydney, Australia and the stripe rust trial at Toluca CIMMYT, Mexico. To confirm the purity of each isolate used in the greenhouse, a wheat stripe rust differential set was used and in the field the barley genotypes Gus, Kaputar, and Maritime were used as susceptible controls for testing $P$. hordei, P. striiformis f. sp. hordei, and P. striiformis f. sp. pseudo-hordei, respectively.

Seedling inoculation procedures. Seedlings were grown ( 8 to 10 per RIL) in $9 \mathrm{~cm}$ plastic pots (two lines/pot) containing a potting mix comprising composted pine bark and coarse sand in a ratio of $4: 1$. Pots were fertilized with a soluble nitrogenous fertilizer Aquasol (Hortico Pty Ltd., Australia) at the rate of $30 \mathrm{~g}$ in 10 liters of water for 200 pots prior to sowing. Plants were maintained both before and after inoculation in a naturally lit, temperature controlled greenhouse $\left(17\right.$ to $\left.22^{\circ} \mathrm{C}\right)$. Approximately $20 \mathrm{mg}$ of urediniospores were suspended in $10 \mathrm{ml}$ of light mineral oil (IsoparL, Univar, NSW, Australia) and sprayed with a mist atomizer. Inoculated seedlings were misted lightly with double distilled water (to maintain leaf wetness for spore germination) and incubated overnight at 9 to $12^{\circ} \mathrm{C}$ in an enclosed chamber in the dark.

Disease assessment for seedling tests. Disease response was assessed 16 to 18 days postinoculation, using a 0 to 4 infection type (IT) scale as described for $P$. striiformis $\mathrm{f}$. sp. tritici by McIntosh et al. (1995), where $0=$ no visible symptoms, $;=$ necrotic flecks, $; \mathrm{N}=$ necrotic areas without sporulation, $1=$ necrotic and chlorotic areas with restricted sporulation, $2=$ moderate sporulation with necrosis and chlorosis, $3=$ sporulation with chlorosis, and $4=$ abundant

TABLE 1. Details of Puccinia rust pathogen isolates used for quantitative trait loci mapping of resistance in the Pompadour/Biosaline-19 mapping population

\begin{tabular}{|c|c|c|c|c|c|}
\hline Pathogen & Plant stage & Location of testing & Pathotype $^{\mathrm{a}}$ & $\begin{array}{c}\text { Accession } \\
\text { number }\end{array}$ & Virulent to \\
\hline P. striiformis f. sp. tritici & Greenhouse & Cobbitty, Australia & $\begin{array}{l}104 \mathrm{E} 137 \mathrm{~A}- \\
134 \mathrm{E} 16 \mathrm{~A}+ \\
64 \mathrm{E} 0 \mathrm{~A}-\end{array}$ & $\begin{array}{l}821559 \\
21510 \\
91937\end{array}$ & $\begin{array}{l}Y r 2, Y r 3, Y r 4, Y r 25 \\
Y r 2, Y r 6, Y r 7, Y r 8, Y r 9, Y r 25, Y r A \\
Y r 4\end{array}$ \\
\hline $\begin{array}{l}\text { P. striiformis } \mathrm{f} . \mathrm{sp} . \\
\text { pseudo-hordei }\end{array}$ & $\begin{array}{l}\text { Greenhouse and } \\
\text { field }\end{array}$ & Cobbitty, Australia & & $981549^{b}$ & na \\
\hline P. striiformis f. sp. hordei & Field & Toluca, Mexico & $\begin{array}{l}\text { P. striiformis f. sp. hordei } \\
\text { race } 24\end{array}$ & Unknown & \\
\hline
\end{tabular}

\footnotetext{
a Tested on differential genotypes carrying $Y r 1, Y r 2, Y r 3, Y r 4, Y r 5, Y r 6, Y r 7, Y r 8, Y r 9, Y r 10, Y r 15, Y r 17, Y r 24, Y r 25, Y r 32$, and complementary genes $(Y r 73$ and Yr74).

b Standard isolate of P. striiformis f. sp. pseudo-hordei.
} 
sporulation without chlorosis. Where plants with two or more distinctly different low ITs were observed, data were recorded and separated with a comma (e.g., IT $=1,1+$, and IT $=3,3+$ ). Plants with ITs of 3 or higher were considered susceptible (McIntosh et al. 1995). The presence of chlorosis (C) or necrosis (N) when distinctive was incorporated into the numerical ( 0 to 4 ) score described by (McIntosh et al. 1995) as part of the description for the different resistance reactions but was not factored into the QTL analysis. For QTL analysis IT data were converted to a numeric quantitative scale. Variations between the ITs ( 0 to 4$)$ were indicated by use of,-+ , and were incorporated by the addition or subtraction of 0.25 (i.e., +) and 0.5 (i.e., ++). For instance, those barley lines that exhibited ITs; and 2C were scored as a 0.5 and 2, respectively. Phenotypic readings were taken at 16 and 18 days following inoculation and averaged. At least three experimental replicates were performed using all population/isolate combinations in the greenhouse. The mean phenotypic score of each individual for the respective mapping populations across all readings and replicates was used for QTL mapping.

Field assessment for resistance to $P$. hordei, $P$. striiformis f. sp. hordei, and $P$. striiformis f. sp. pseudo-hordei in the P/B-19 population. Approximately 20 to 30 seeds of each RIL and both parental lines were sown in $0.7 \mathrm{~m}$ rows at $0.3 \mathrm{~m}$ spacing in early May 2015 and 2016 seasons. For the P. striiformis f. sp. pseudo-hordei assessment, the susceptible barley cultivar Maritime was sown after every five plots of test lines to assist uniform inoculum increase and spread across the experimental areas. Wheat cultivar Avocet S (immune to $P$. striiformis f. sp. pseudo-hordei, but highly susceptible to $P$. striiformis f. sp. tritici) was used to monitor potential contamination by $P$. striiformis f. sp. tritici in the BGYR disease nursery. Adult plant responses to $P$. hordei were also assessed in 2016 as a positive control for the genetic mapping studies and the leaf rust-susceptible barley genotype Gus was used in disease spreader rows and sown after every five plots of test lines.

Epidemics were achieved by inoculating the nurseries with a urediniospore-mineral oil suspension (mixing ratio of $30 \mathrm{mg}$ of spores in 1.5 liter of Isopar L-mineral oil, Univar, Ingleburn, NSW, Australia). For both $P$. horde $i$ and $P$. striiformis f. sp. pseudo-hordei, the same isolates were used in field assessments as in greenhouse seedling tests. Inoculum was sprayed over spreader rows using an ultra-low volume applicator (Microfit, Micron sprayer Ltd., Bromyard, Herefordshire, UK). At least three successive inoculations were performed in each year during afternoons when there was high chance of overnight dew.

A modified Cobb scale (Peterson et al. 1948) was used to assess disease severity (measured as percent leaf area affected) and host response, where $\mathrm{R}=$ no uredinia present; $\mathrm{TR}=$ trace or minute uredinia on leaves without sporulation; $\mathrm{MR}=$ small uredinia with slight sporulation; MR-MS = small to medium size uredinia with moderate sporulation; $\mathrm{MS}-\mathrm{S}=$ medium size uredinia with moderate to heavy sporulation; $\mathrm{MS}=$ medium size uredinia with moderate sporulation; $\mathrm{S}=$ large uredinia with abundant sporulation. When the highest disease levels of 90 to 100 S ( 90 to $100 \%$ of leaf area infected with large pustules) were reached on the susceptible checks the plants were scored. For each year, data were recorded three times, but the third (highest disease score) rating was used for analysis. A coefficient of infection (CI) was gained from the host response and disease severity by multiplying the disease severity score measured according to Cobb scale by a predetermined value of $0.15,0.30$, $0.45,0.60,0.75$, and 1.0 given to the host response ratings of $\mathrm{R}, \mathrm{MR}$, MR/MS, MS, MS/S, and S, respectively (Golegaonkar 2007).

Marker genotyping of P/B-19 mapping population. Genomic DNA was extracted from young leaf tissue using the protocol recommended by Diversity Arrays Technology Pty. Ltd. (DArT; www.diversityarrays.com). The samples submitted to DArT for genotyping consisted of single plants from both parents and 92 randomly selected genotypes from 98 RILs in the P/B-19 mapping population. In total, 94 individuals were genotyped with DArT-Seq markers using the Barley GBS 1.0 platform, which returned 16,200 polymorphic in silico DArT-Seq presence or absence markers. The centimorgan (cM) positions for all polymorphic DArT-Seq markers in the $\mathrm{P} / \mathrm{B}-19$ population were determined based on the position in the Bowman consensus map provided by DArT as part of their genotypic service (Supplementary Table S1).

QTL analysis in the $\mathrm{P} / \mathrm{B}-19$ mapping population. Polymorphic markers were selected every $5 \mathrm{cM}$ based on genetic positions from the Bowman consensus genetic map provided by DArT. Single marker regression (SMR) was used initially to identify significant associations with selected genetic markers with each trait to give an indication for the location of QTL. Composite interval mapping (CIM) methods were then used to identify and confirm the presence of QTL using QTL Cartographer v2.5 software (Wang et al. 2013). Permutation analysis (1,000 iterations) was used to establish an experiment-wise significance value at the 0.05 confidence level, defined as a minimum LOD threshold for each trait in CIM (Churchill and Doerge 1994; Doerge and Churchill 1996). The maximum LOD score of association between the genotype and trait data were calculated for CIM, and QTL location predictions were accepted for CIM for values greater than a threshold value of 2.5. QTL regions associated with resistance to different $P$. striiformis isolates in the $\mathrm{P} / \mathrm{B}-19$ mapping population were considered to be the same if there was overlap between their LOD-1 support intervals based on the genetic positions on the Bowman consensus map.

Genotypic analysis for APR to $P$. hordei. The parents of the P/B-19 mapping population, Pompadour and Biosaline-19, were genotyped with two previously published molecular markers linked to leaf rust APR genes Rph20 ( $b P b-0837)$ and Rph23 (Ebmac0603) as described by Hickey et al. (2011) and Singh et al. (2015), respectively, to determine the presence/absence of each locus

TABLE 2. Seedling infection type data for the parents and selected recombinant inbred lines (RILs) from the barley Pompadour/Biosaline-19 mapping population in response to three Puccinia striiformis f. sp. tritici pathotypes, $P$. striiformis f. sp. pseudo-hordei, and P. hordei

\begin{tabular}{|c|c|c|c|c|c|}
\hline $\begin{array}{l}\text { Barley/wheat } \\
\text { lines }\end{array}$ & \multicolumn{4}{|c|}{ Infection type ${ }^{a}$} & P. hordei ${ }^{\mathrm{b}}$ \\
\hline Biosaline-19 & $3+$ & 3 & 3 & 3 & $3+$ \\
\hline RIL18 & $2+\mathrm{C}$ & ;C & 0 & 0 & $3+$ \\
\hline RIL22 & $3+$ & $2+\mathrm{CN}$ & $1 \mathrm{CN}$ & $1+\mathrm{CN}$ & $3+$ \\
\hline RIL60 & $3+$ & $0 ;, ; \mathrm{C}$ & ;CN & $; 1 \mathrm{CN}$ & $3+$ \\
\hline
\end{tabular}

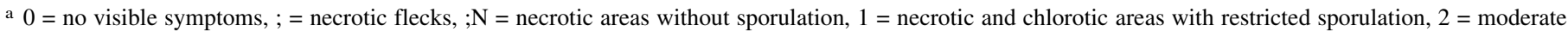
sporulation with necrosis and chlorosis, $3=$ sporulation with chlorosis, and $4=$ abundant sporulation without chlorosis. Variations of the infections types are indicated by use of - (less than average for the class), + (more than average for the class), $\mathrm{C}$ (chlorosis), and/or $\mathrm{N}$ (necrosis).

b Pathotype $5457 \mathrm{P}+$. 
within the parental genotypes. For Ebmac0603, Yerong (Rph23) and Franklin (rph23) were used as positive and negative controls, respectively, while for $b P b-0837$, barley genotypes Flagship $(R p h 20)$ and Gus (rph20) were used as positive and negative controls, respectively.

Histological assessment of $\boldsymbol{P}$. striiformis f. sp. tritici and $P$. striiformis f. sp. pseudo-hordei on barley. Histological analysis was performed on both parental genotypes of the P/B-19 mapping population, RIL18, and wheat control accession Avocet $\mathrm{S}$ using P. striiformis f. sp. pseudo-hordei and P. striiformis f. sp.tritici pathotypes (104 E137 A- and 134 E16 A+). The histology was performed essentially as described by Ayliffe et al. (2011). In brief, leaf tissue samples from rust-infected barley plants were harvested and autoclaved in $1 \mathrm{M} \mathrm{KOH}$, and then neutralized by washing the material twice with $50 \mathrm{mM}$ Tris, $\mathrm{pH} 7.5$. After neutralization, tissue samples were stained with $20 \mu \mathrm{g}$ of fluorescent wheat germ agglutinin (WGA-FITC) for $20 \mathrm{~min}$ at room temperature, rinsed in water, and then placed on to a microscope slide using a flat spatula. Water was gently sprayed on to the surface of the leaf segments to unfold and straighten out before being subjected to microscopy under UV light excitation.

\section{RESULTS}

Parental responses to heterologous $\boldsymbol{P}$. striiformis isolates. Pompadour was immune at both the seedling $(0 ;)$ and adult (1R) developmental stages to $P$. striiformis f. sp. pseudo-hordei and also immune $(0 ;)$ to all three $P$. striiformis f. sp. tritici pathotypes (104 E137 A-, 134 E16 A+, and 64 E0 A-) at the seedling stage. In contrast, B-19 was susceptible to all four $P$. striiformis isolates used at both the seedling stage in greenhouse tests and at the adult plant stage in the field. (Table 2; Figs. 1 and 2). Pompadour was seedling susceptible (IT 3 ) to the pathotype of $P$. hordei used in field assessments (viz. $5457 \mathrm{P}+$ ) and was highly resistant (10MR) at the adult plant stage, while B-19 was susceptible (3+ and 90S) at all growth stages (Table 2).
Greenhouse phenotypic studies of the P/B-19 mapping population. The $\mathrm{P} / \mathrm{B}-19$ mapping population was assessed in the greenhouse with the three diverse $P$. striiformis f. sp. tritici pathotypes 104 E137 A-, 134 E16 A+, and 64 E0 A- and P. striiformis f. sp. pseudo-hordei. A wide range of infection types (ITs) was observed among the RILs, ranging from immunity (IT = 0;) to complete susceptibility (IT = 3+), suggesting that the inheritance of resistance within the population was complex and likely under polygenic control (Fig. 1; Table 2). The frequency distribution of phenotypic response to all $P$. striiformis isolates tested showed continuous variation that skewed toward resistance

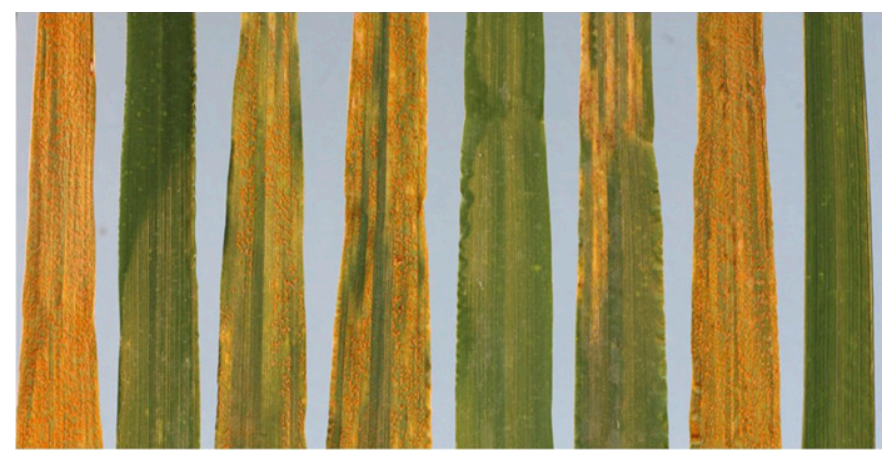

Fig. 2. Adult plant response of (left to right) Biosaline-19 (susceptible parent), Pompadour (resistant parent), RIL31 (20MR), RIL42 (40MS), RIL43 (1R), RIL47 (TR), RIL22 (90S), and Avocet S when tested in the field against Puccinia striiformis f. sp. pseudo-hordei (isolate 981549). Modified Cobb scale (Peterson et al. 1948) was used to assess disease severity (measured as percent leaf area affected) and host response where $\mathrm{R}=$ no uredinia present; $\mathrm{TR}=$ trace or minute uredinia on leaves without sporulation; $\mathrm{MR}=$ small uredinia with slight sporulation; MRMS = small to medium size uredinia with moderate sporulation; $\mathrm{MS}=$ medium sized uredinia with moderate sporulation; MSS $=$ medium size uredinia with moderate to heavy sporulation; and $\mathrm{S}=$ large uredinia with abundant sporulation.
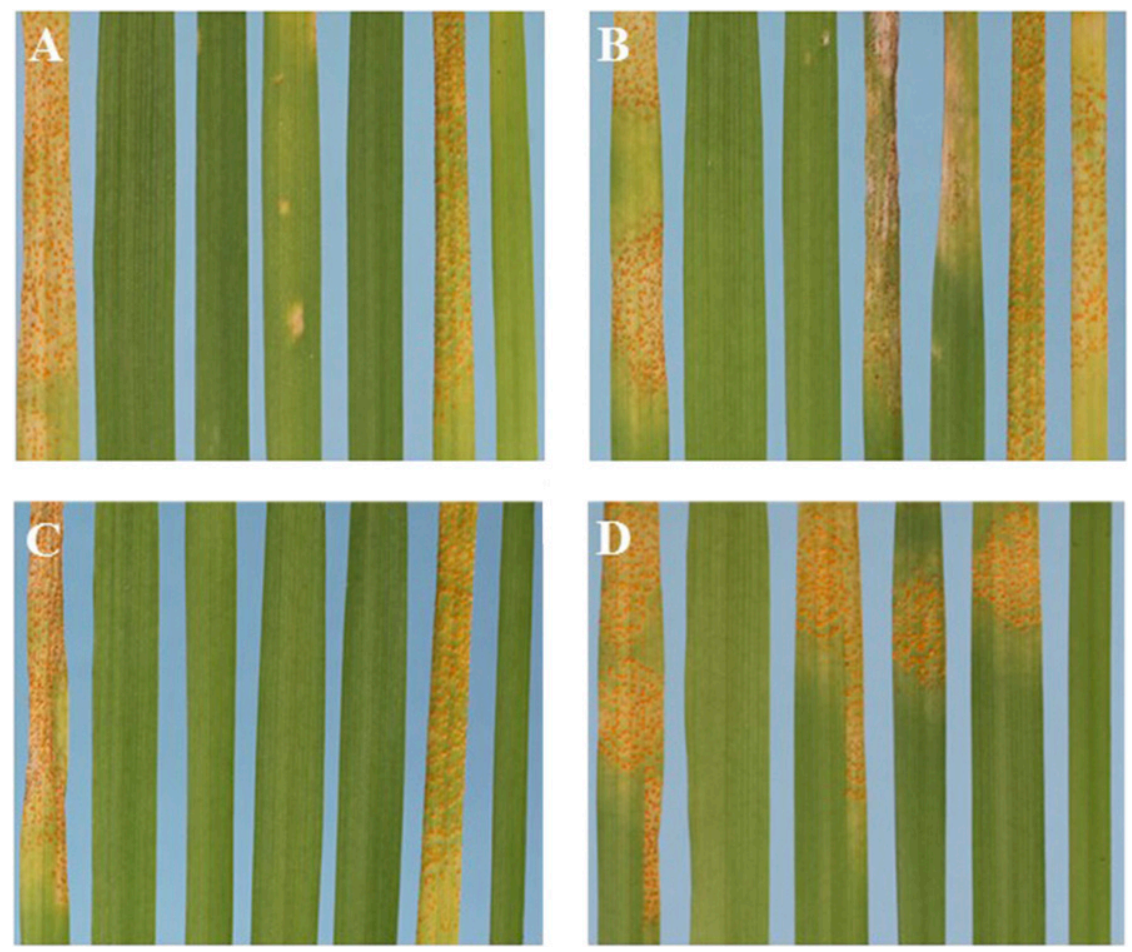

Fig. 1. Seedling leaves 18 days postinoculation with A, Puccinia striiformis $\mathrm{f}$. sp. tritici 104 E137 A-, B, P. striiformis f. sp. tritici 134 E16 A+, C, P. striiformis f. sp. tritici 64 E0 A- (left to right: Biosaline-19, Pompadour, RIL18, RIL22, RIL60, Avocet S (Yr73), and Avocet near isogenic line for Yr9) and D, P. striiformis f. sp. pseudo-hordei (isolate 981549) (left to right: Biosaline-19, Pompadour, RIL18, RIL22, RIL60, and Avocet S [Yr73]). 
(Fig. 3A), further supporting the involvement of multiple resistance genes. More RILs were susceptible to P. striiformis f. sp. pseudohordei compared with $P$. striiformis $\mathrm{f}$. sp. tritici, suggesting that the inheritance of resistance to $P$. striiformis $\mathrm{f}$. sp. tritici was more complex than that for $P$. striiformis f. sp. pseudo-hordei. Four genotypes (RILs 18, 22, 60, and 94) showed isolate-specific resistance (ITs ranging from 0 ; to $; \mathrm{CN}$ ) to the three $P$. striiformis $\mathrm{f}$. sp. tritici pathotypes, but were susceptible to $P$. striiformis $\mathrm{f}$. sp. pseudo-hordei (Fig. 1).

Assessment of field resistance to $P$. striiformis f. sp. pseudo-hordei, P. hordei, and P. striiformis f. sp. hordei. The P/B-19 mapping population was assessed in the field for resistance to $P$. striiformis f. sp. pseudo-hordei and P. hordei at Cobbitty,
Australia and P. striiformis f. sp. hordei at Toluca, Mexico. We assessed leaf rust resistance in the P/B-19 mapping population in 2016 only as a positive control for QTL mapping and to determine whether Rph20 in the Pompadour parent was likely to colocate with the QTL identified for resistance to both adapted and heterologous $P$. striiformis isolates. We also aimed to map APR in response to $P$. striiformis f. sp. pseudo-hordei based on comparison with the greenhouse-derived seedling resistance data to the same isolate. Continuous variation was observed in the P/B-19 mapping population in both years in response to $P$. striiformis $\mathrm{f}$. sp. pseudohordei, in which the level of resistance varied from complete immunity (1R) to susceptibility (90 to 100S) (Figs. 2 and 3B). A small number of RILs (RIL16, RIL24, and RIL73) were susceptible

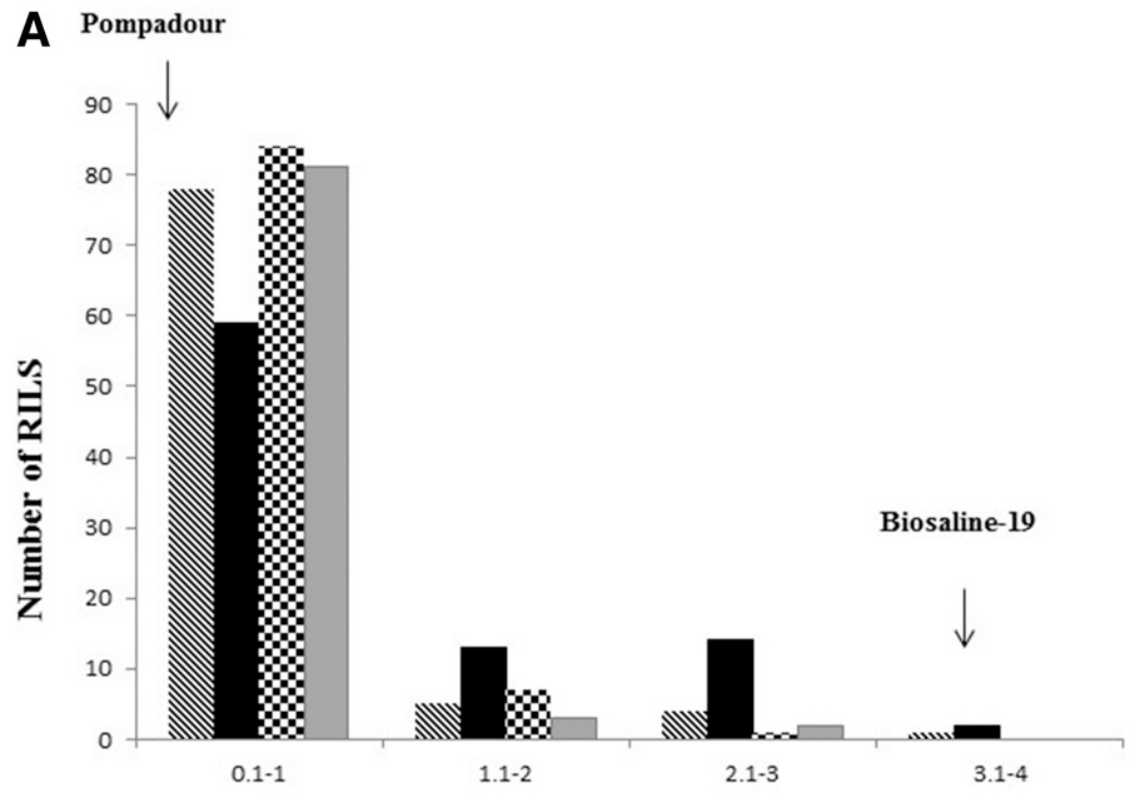

Infection response score

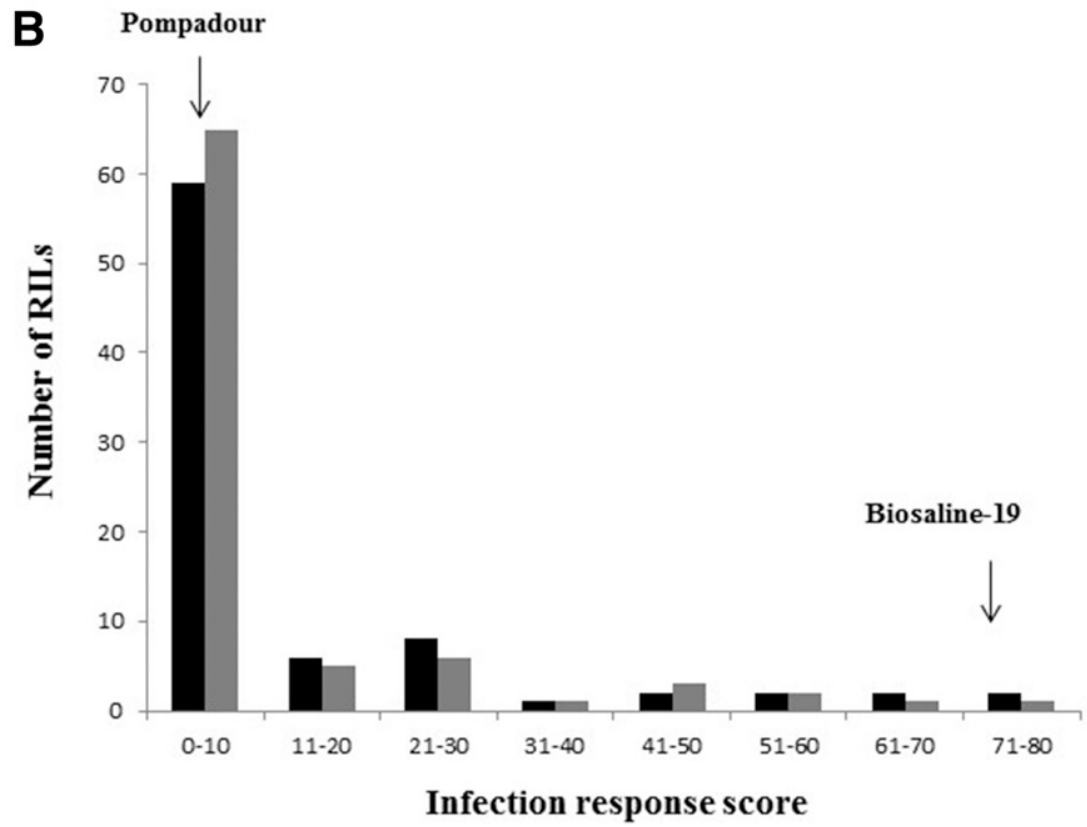

Fig. 3. Frequency distribution of infection response of 98 P/B-19 RILs at A, seedling stage to Puccinia striiformis f. sp. pseudo-hordei (isolate 981549 ) (black) and three P. striiformis f. sp. tritici: P. striiformis f. sp. tritici isolates 104 E137 A- (large checker board), 134 E16 A+ (downward diagonal), and 64 E0 A- (gray) and B, adult plant resistance to P. striiformis f. sp. pseudo-hordei in 2 years: 2015 (black) and 2016 (gray), scored using Cobb scale and converted to coefficient of infection. Disease response values for parents are indicated by arrows. 
as seedlings but were resistant in the field, indicating that they carried APR (Figs. 2 and 3B).

Genotyping with markers closely linked to leaf rust APR genes $R p h 20$ and $R$ ph 23. To test the possible pleiotropic involvement of $R p h 20$ in the field resistance observed in response to $P$. striiformis f. sp. pseudo-hordei and P. striiformis f. sp. hordei, both parents and the P/B-19 population were genotyped with closely linked $R p h 20$ marker, $b P b-0837$. Pompadour was positive for the Rph20 marker allele $b P b-0837$ (245 bp as observed in positive control cultivar Flagship) while the B-19 parent was negative, supporting segregation of Rph20 within the P/B-19 mapping population. Further genotypic analysis of the P/B-19 mapping population determined that 50 RILs carried the $b P b-0837$ marker allele and 42 lacked the marker allele $\left(\chi^{2}[1: 1]=0.70\right.$ at $\left.1 \mathrm{df} ; P>0.4\right)$ (Supplementary Table S2). Despite rare exceptions (two susceptible RILs), all leaf rust resistant RILs in season 2016 carried the $b P b$ 0837 marker allele (Fig. 4). In contrast, there was no association between the presence of $b P b-0837$ and resistance to $P$. striiformis f. sp. pseudo-hordei and P. striiformis f. sp. hordei (Fig. 4). This was further supported by contingency $\chi^{2}$ analysis, which revealed a lack of association between the presence of $R p h 20$ linked marker allele $b P b-0837$ and resistance to $P$. striiformis f. sp. hordei $\left(\chi^{2}\right.$ [independence] $=2.47, P>0.12[1 \mathrm{df}])$ and $P$. striiformis f. sp. pseudo-hordei $\left(\chi^{2}\right.$ [independence] $=0.28, P>0.60$ [1 df]) (Supplementary Table S3). The parents were also genotyped with codominant marker Ebmac0603 to determine the likely presence of the minor leaf rust APR locus Rph23. Neither parent carried the same sized allele as Yerong (Rph23), B-19 had the same sized allele as Franklin (Rph23) while Pompadour appeared to have a marginally smaller band size possibly due to the absence of one or two SSR repeat motifs (data not shown).

QTL analysis and mapping of resistance to $P$. striiformis in P/B-19 RILs. Analyses of seedling data (Supplementary Table S4) from greenhouse tests using P. striiformis f. sp. pseudo-hordei and all three $P$. striiformis $\mathrm{f}$. sp. tritici pathogen isolates identified six resistance loci spread across four different chromosomes. Four of the six resistance loci identified were effective to multiple $P$. striiformis isolates and/or $P$. striiformis $\mathrm{f}$. sp. For example,

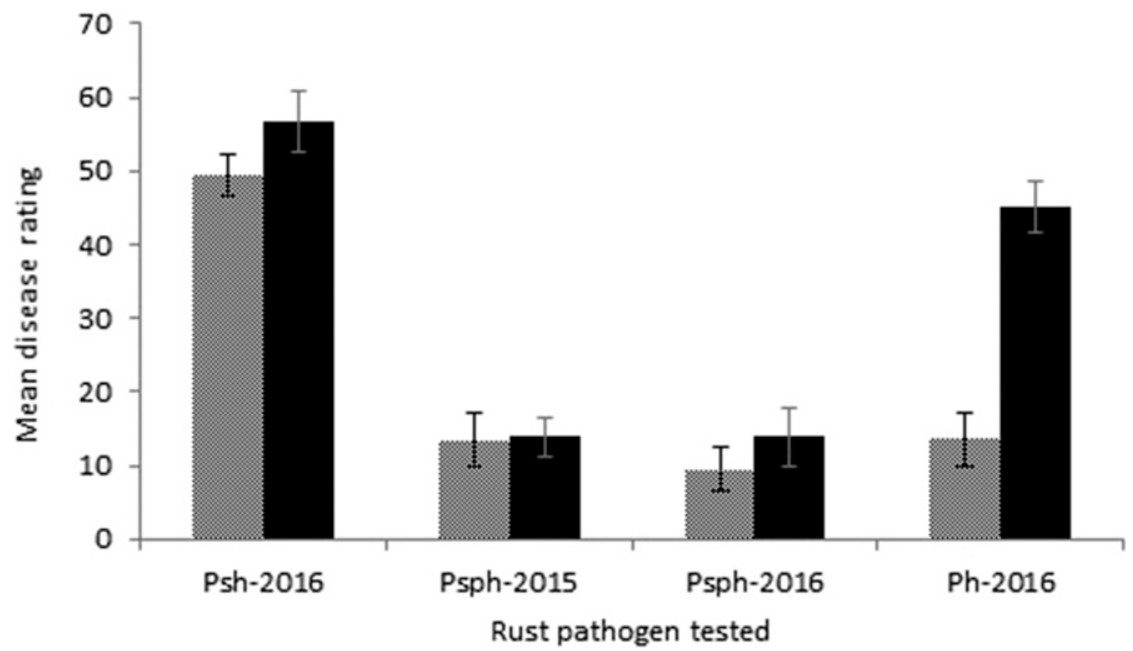

Fig. 4. Bars represent the mean coefficient of infection for recombinant inbred lines (RILs) of the P/B-19 mapping population that either carry (black) or lack (gray) the closely linked marker for adult plant resistance gene Rph20 (bPb-0837) based on phenotypic assessment with Puccinia striiformis f. sp. hordei (Psh), $P$. striiformis f. sp. pseudo-hordei $(P s p h)$, and $P$. hordei $(P h)$. Error bars represent the standard error of the phenotypic scores for all RILs either carrying or lacking the bPb-0837 marker allele.

TABLE 3. Summary table of quantitative trait loci (QTL) for resistance to both adapted Puccinia hordei and heterologous (P. striiformis f. sp. tritici and $P$. striiformis f. sp. pseudo-hordei) cereal rust pathogen isolates at the seedling and/or adult plant stage in the Pompadour/Biosaline-19 recombinant inbred line mapping population

\begin{tabular}{|c|c|c|c|c|c|c|c|}
\hline Growth stage, trait & QTL & Chr & Position (cM) & Peak LOD & Peak marker & LOD-1 interval (cM) & $\begin{array}{c}\% \text { Phenotypic } \\
\text { variance explained }\end{array}$ \\
\hline \multicolumn{8}{|l|}{ Seedling } \\
\hline \multirow{3}{*}{ P. striiformis f. sp. pseudo-hordei } & Rpsphq1 & $1 \mathrm{H}$ & 4.97 & 7.12 & 4013186 & $4.97-5.97$ & $19 \%$ \\
\hline & Rpsphq2 & $3 \mathrm{H}$ & 144.26 & 3.38 & 4790430 & $141.62-146.26$ & $15.5 \%$ \\
\hline & Rpsphq3 & $5 \mathrm{H}$ & 75.88 & 6.30 & 3267647 & $73.88-77.88$ & $19 \%$ \\
\hline \multirow[t]{3}{*}{ P. striiformis f. sp. tritici 134 E16 A+ } & Rpstq2 & $3 \mathrm{H}$ & 49.30 & 2.82 & 3266870 & $47.49-51.30$ & $13 \%$ \\
\hline & Rpstq3 & $5 \mathrm{H}$ & 76.88 & 3.06 & 3267647 & $72.98-82.58$ & $9 \%$ \\
\hline & Rpstq5 & $7 \mathrm{H}$ & 130.71 & 7.72 & 3265004 & $130.08-132.71$ & $23 \%$ \\
\hline \multirow[t]{3}{*}{ P. striiformis f. sp. tritici 104 E137 A- } & Rpstq1 & $1 \mathrm{H}$ & 4.97 & 3.89 & 4013186 & $4.01-5.97$ & $10 \%$ \\
\hline & Rpstq4 & $5 \mathrm{H}$ & 92.16 & 6.47 & 3272545 & $89.57-93.16$ & $18 \%$ \\
\hline & Rpstq5 & $7 \mathrm{H}$ & 130.71 & 6.18 & 3265004 & $130.08-132.71$ & $18 \%$ \\
\hline \multirow{2}{*}{ P. striiformis f. sp. tritici $64 \mathrm{E} 0 \mathrm{~A}-$} & Rpstq4 & $5 \mathrm{H}$ & 93.16 & 2.71 & 3272545 & $89.57-96.16$ & $12 \%$ \\
\hline & Rpstq5 & $7 \mathrm{H}$ & 130.71 & 5.58 & 3265004 & $130.08-132.71$ & $20 \%$ \\
\hline \multicolumn{8}{|l|}{ Adult } \\
\hline \multirow[t]{3}{*}{ P. striiformis f. sp. pseudo-hordei 2015} & Rpsphq1 & $1 \mathrm{H}$ & 11.77 & 3.32 & 6437473 & $3.97-5.77$ & $11 \%$ \\
\hline & Rpsphq4 & $5 \mathrm{H}$ & 91.57 & 5.08 & 3272545 & $88.57-92.16$ & $17 \%$ \\
\hline & Rpsphq6 & $7 \mathrm{H}$ & 33.35 & 3.48 & 4000096 & $31.35-35.42$ & $14 \%$ \\
\hline \multirow[t]{4}{*}{ P. striiformis f. sp. pseudo-hordei 2016} & Rpsphq1 & $1 \mathrm{H}$ & 4.97 & 5.17 & 4013186 & $4.01-5.97$ & $16 \%$ \\
\hline & Rpsphq3 & $5 \mathrm{H}$ & 75.90 & 5.33 & 3267647 & $72.98-78.88$ & $19 \%$ \\
\hline & Rpsphq5 & $7 \mathrm{H}$ & 6.01 & 2.92 & 3270408 & $2.01-9.46$ & $9 \%$ \\
\hline & Rpsphq6 & $7 \mathrm{H}$ & 35.35 & 4.33 & 4000094 & $33.35-37.42$ & $14 \%$ \\
\hline Puccinia hordei 2016 & Rphql & $5 \mathrm{H}$ & 14.91 & 9.85 & 3267552 & $11.41-17.19$ & $32 \%$ \\
\hline
\end{tabular}


multiple QTL for resistance to all $P$. striiformis isolates tested were mapped in a region on chromosome $5 \mathrm{HL}$ spanning 60 to $90 \mathrm{cM}$. Furthermore, multiple QTL for resistance to both P. striiformis $\mathrm{f}$. sp. tested were also mapped on chromosome 1HS, however, for $P$. striiformis f. sp. tritici the resistance was isolate-specific and only effective to one of the P. striiformis f. sp. tritici isolates (104 E137 A-) (Table 3; Fig. 5). A further two QTL on chromosome 3HS (P. striiformis f. sp. tritici $134 \mathrm{E} 16 \mathrm{~A}+$ ) and $3 \mathrm{HL}$ (P. striiformis f. sp. pseudo-hordei) of minor effect were isolate-specific, being effective to only a single isolate (Fig. 5). A major effect QTL accounting for up to $25.31 \%$ of the phenotypic variation was identified on chromosome $7 \mathrm{HL}$ in response to all $P$. striiformis $\mathrm{f}$. sp. tritici isolates but not to $P$. striiformis f. sp. pseudo-hordei, suggesting the presence of gene(s) only effective to the wheat adapted P. striiformis isolates.

Field-derived phenotypic data for the P/B-19 mapping population in response to $P$. hordei (2016), and P. striiformis f. sp. pseudo-hordei
$1 \mathrm{H}$

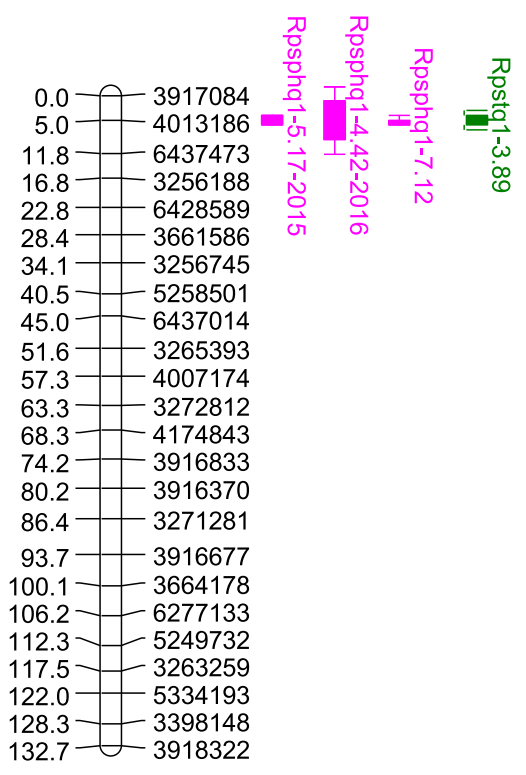

3H
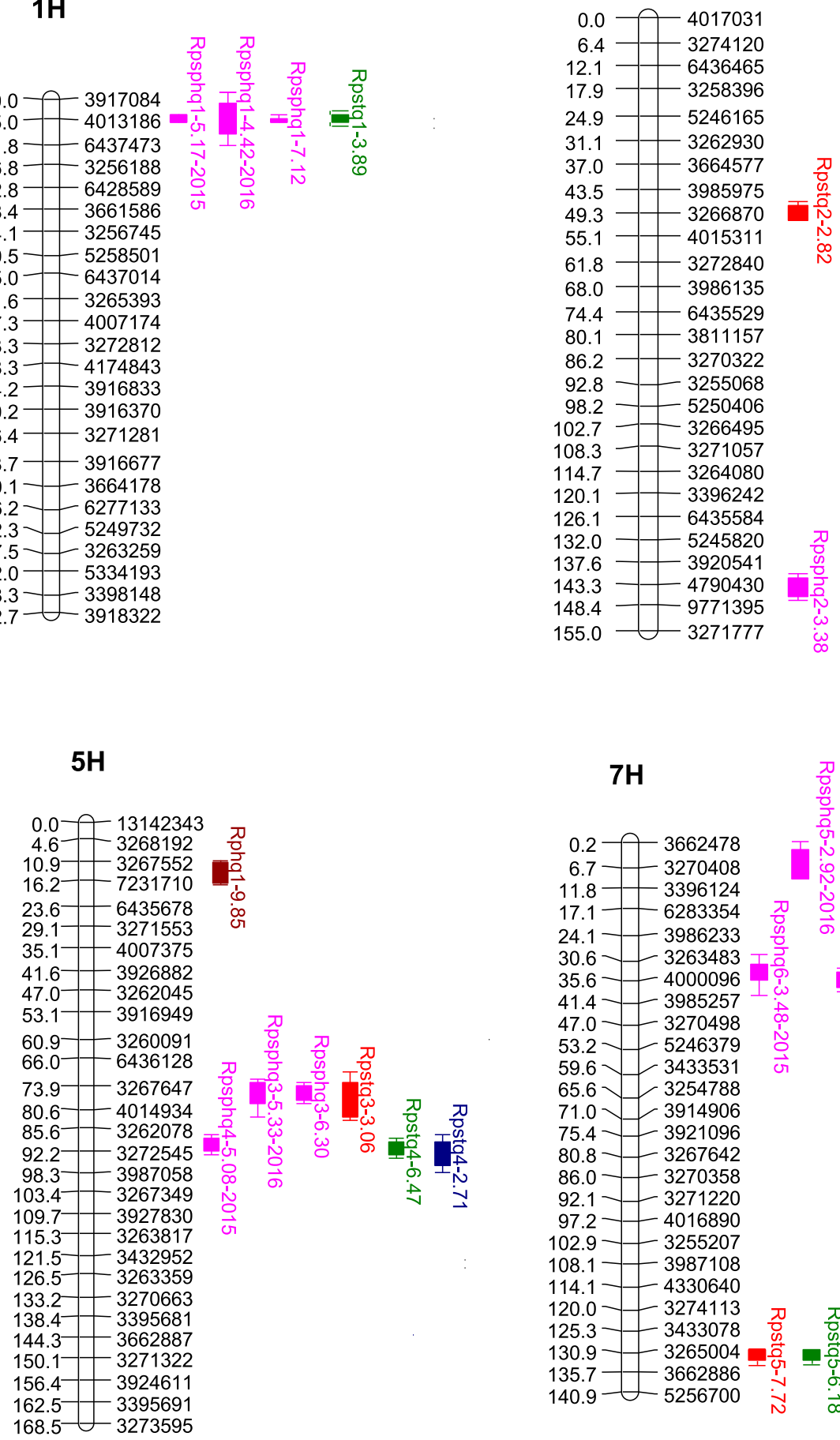

7H

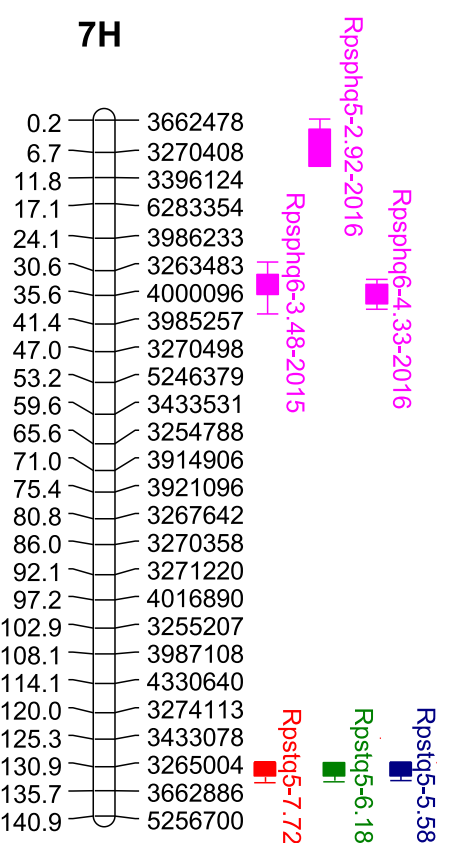

Fig. 5. Quantitative trait loci (QTL) for resistance on chromosomes $1 \mathrm{H}, 2 \mathrm{H}, 3 \mathrm{H}, 5 \mathrm{H}$, and $7 \mathrm{H}$ in the Pompadour/Biosaline-19 mapping population at the seedling stage to three Puccinia striiformis f. sp. tritici pathotypes (104 E137 A- [green], 134 E16 A+ [red], and 64 E0 A- [blue]), and P. striiformis f. sp. pseudo-hordei (Psph-pink) and in the field at the adult plant stage to P. striiformis f. sp. pseudo-hordei (Psph) and P. hordei (Ph-purple). The name on QTL bars has two components: the provisional name of the gene at the QTL and the logarithm of odds (LOD) value recorded for the QTL. For QTLs derived from field studies, the year of assessment is also included in the QTL name. The length of the colored solid bars indicates the LOD-1 confidence intervals and the QTL lines are extended to the LOD-2 confidence intervals. 
(2015 and 2016) was used to map adult plant responses to $P$. hordei and $P$. striiformis f. sp. pseudo-hordei and to compare the chromosomal location with known leaf rust resistance on chromosome 5HS (Rph20-used as positive control for QTL mapping). For P. striiformis f. sp. hordei, three QTL were mapped using field data from Toluca in Mexico with $P$. striiformis $\mathrm{f}$. $\mathrm{sp}$. hordei race 24 on chromosomes $1 \mathrm{H}, 2 \mathrm{H}$, and $5 \mathrm{H}$, the $5 \mathrm{H}$ QTL was on a different chromosome arm than the 5HS leaf rust resistance QTL corresponding to Rph20 (data not shown). At the adult plant stage (2016) QTLs for resistance to $P$. striiformis f. sp. pseudo-hordei were mapped on chromosomes 1H (Rpsphq1-both 2015 and 2016) and 5H (Rpsphq3-2016- and Rpsphq4-2015) at the same position as the QTL identified from the greenhouse assessments at the seedling stage. The 2015 QTL for adult plant stage (-Field2015-5.08) shared the same peak marker with seedling resistance QTL for $P$. striiformis $\mathrm{f}$. $\mathrm{sp}$. tritici isolates (104 E137 A- and 64 E0 A-), suggesting the involvement of all-stage resistance genes (Table 3; Fig. 5). Additional QTL were also mapped on chromosome 7HS using the field response data from both 2015 and 2016 at $35.35 \mathrm{cM}$ to the same location as previously characterized APR gene Rph23. The 7HS QTL was not identified at the seedling stage and therefore represents a locus conferring APR to P. striiformis f. sp. pseudo-hordei.

Histology of infection of $\boldsymbol{P}$. striiformis on barley. Histology was performed on both parents (Pompadour and B-19) and RIL18 (differential response to $P$. striiformis isolates) and wheat accession Avocet $\mathrm{S}$ to critically assess the subtle but apparent differences in infection types observed on RIL18 when challenged with $P$. striiformis f. sp. tritici (pathotypes 134 E16 A+ and $104 \mathrm{E} 137 \mathrm{~A}-$ ) and $P$. striiformis f. sp. pseudo-hordei (Fig. 6). Uredinospores derived from all $P$. striiformis isolates were able to germinate and find stomata on the wheat and barley genotypes. The immunity observed during seedling assessments in Pompadour was due to the absence of any hyphal colonies and what appeared to be a prehaustorial mode of resistance. In contrast, prolific hyphal growth was observed in the B-19 parent with dense clusters of fungal colonies representing pustule formation. The differential macroscopic response observed on RIL18 was observed at the microscopic level as a lack of colonies in response to 134 E16 A+, restricted hyphal growth in response to 104 E137 Aand the same level of hyphal growth in response to $P$. striiformis f. sp. pseudo-hordei as observed in the parent B-19. Prolific hyphal growth was observed on the wheat control Avocet $\mathrm{S}$ for both P. striiformis f. sp. tritici isolates, while no fungal growth was observed after infection with P. striiformis f. sp. pseudo-hordei (Fig. 6).

\section{DISCUSSION}

The division between host and nonhost resistance is not clear-cut. Niks and Marcel (2009) suggested that because pathogens coevolve with radiating plant species, some plant species are intermediate or near nonhosts and could be in the process of transition between host and nonhost status. The susceptibility of the experimental barley line SusPtrit to numerous heterologous rust pathogens has facilitated genetic analysis and fine mapping of QTL for resistance, making the barley-Puccinia pathosystem ideal to investigate mechanisms and evolution of resistance. We developed a $\mathrm{F}_{9}$ barley RIL mapping population based on a cross between the P. striiformissusceptible parent B-19 and the resistant European cultivar Pompadour that also carries APR to leaf rust due to gene Rph2O. We aimed to assess the potential for pleiotropic involvement of Rph20 in stripe rust resistance and the genetic basis and specificity of stripe rust resistance in this population to pathogenically diverse $P$. striiformis isolates adapted to wheat and barley grass.

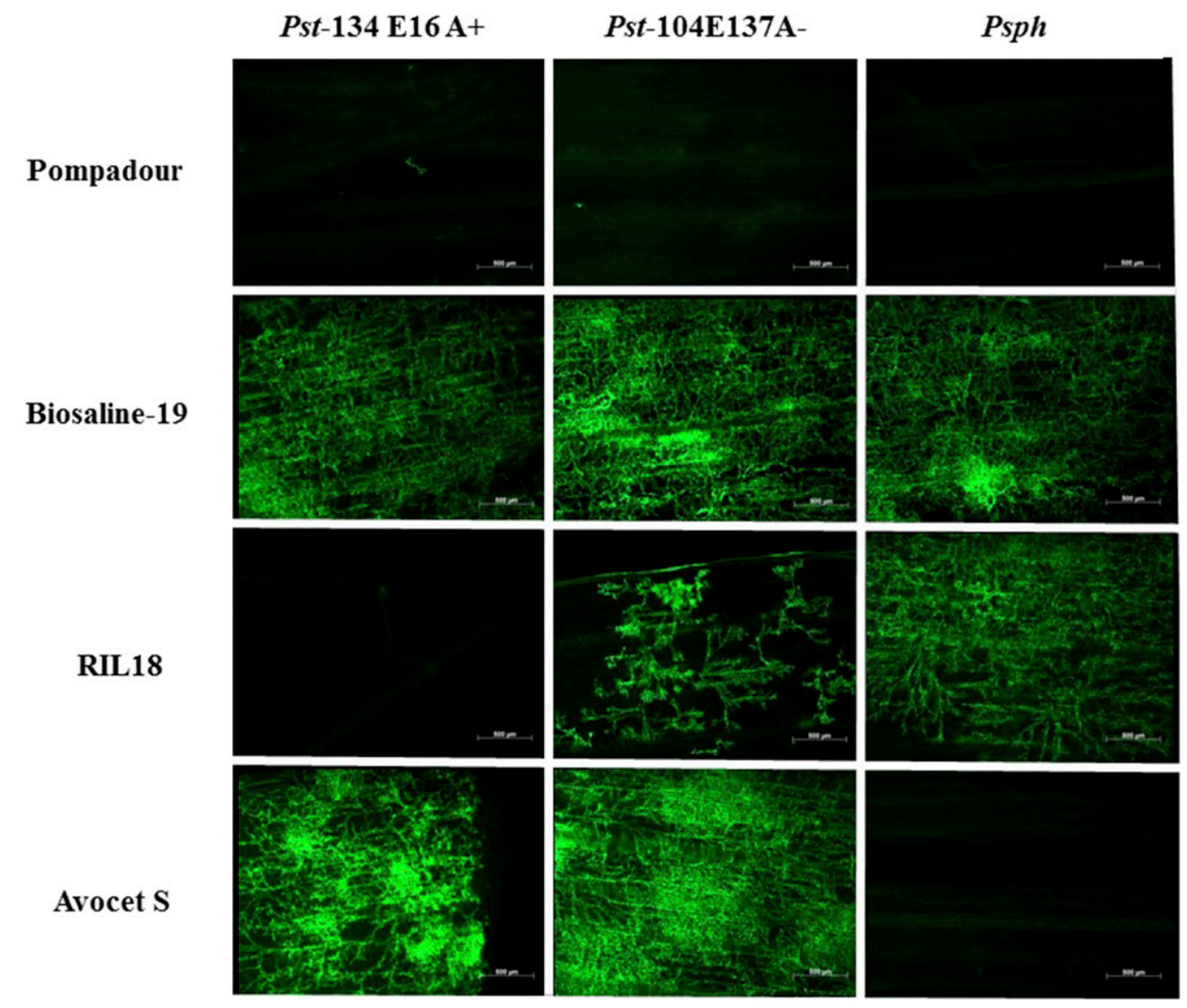

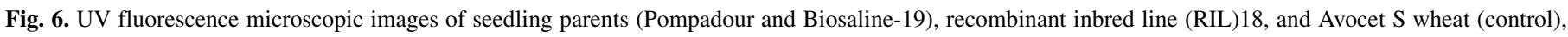

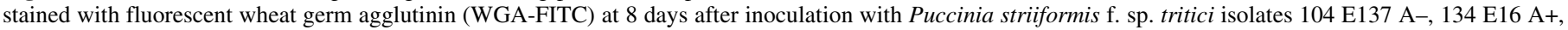
and P. striiformis f. sp. pseudo-hordei (Psph). 
Previous genetic studies on resistance to $P$. striiformis in barley have reported on both polygenic (Derevnina et al. 2015; Dracatos et al. 2015; Kamino et al. 2015; Niks et al. 2015) and monogenic resistance (Pahalawatta and Chen 2005b; Sui et al. 2010). The immunity in barley cultivar Pompadour to the diverse P. striiformis isolates was due to unique sets of QTL that were both isolate-specific and overlapping between the different isolates. We identified a major effect QTL on the long arm of chromosome 7H (Rpstq4) in response to all three $P$. striiformis $\mathrm{f}$. sp. tritici isolates but not $P$. striiformis f. sp. pseudo-hordei. Given that the P. striiformis f. sp. tritici isolates used are considered to be genetically different, this result suggests that the avirulence gene corresponding to Rpstq4 may be fixed in $P$. striiformis f. sp. tritici populations but lacking in the P. striiformis f. sp. pseudo-hordei isolate used in this study. Recent studies by $\mathrm{Li}$ et al. (2016) and Dawson et al. (2016) fine mapped a major effect QTL for resistance to $P$. striiformis f. sp. tritici, Rps6, to $0.14 \mathrm{cM}$ physical interval on chromosome 7HL that colocalized with resistance gene (temporary designation $\operatorname{Yrpst} Y 1$ ), which confers resistance to a Chinese isolate of $P$. striiformis $\mathrm{f}$. sp. tritici in barley (Sui et al. 2010). Furthermore, seedling resistance has also been previously mapped to $7 \mathrm{HL}$ in response to $P$. striiformis isolates adapted to barley (Castro et al. 2003; Dracatos et al. 2015), barley grass (Derevnina et al. 2015; Golegaonkar et al. 2013; Kamino et al. 2015; Zhou and Li 2008), and brome grass (Niks et al. 2015). This either suggests the presence of a single locus providing broad-spectrum resistance to $P$. striiformis that is frequent in barley germplasm or more likely that the region on 7HL harbors numerous genes as reported for NBS-LRR genes in plant species with both differing and overlapping specificities.

Previous studies in barley have identified overlapping specificities of resistance QTL in response to heterologous rust pathogens (Jafary et al. 2008; Marcel et al. 2007; Niks 1986; Niks et al. 2015; Yeo et al. 2015). The QTL identified on chromosomes $1 \mathrm{H}$ (P. striiformis f. sp. pseudo-hordei and P. striiformis f. sp. tritici $104 \mathrm{E} 137 \mathrm{~A}-)$ and 5H (P. striiformis f. sp. pseudo-hordei and all P. striiformis f. sp. tritici isolates) are both examples of overlapping specificities between the wheat and barley grass adapted formae speciales of $P$. striiformis. Brueggeman et al. (2002) determined that the stem rust resistance locus Rpg5 locus in barley on the long arm of chromosome $5 \mathrm{H}$ confers resistance to both $P$. graminis $\mathrm{f}$. sp. tritici and $P$. graminis f. sp. secalis and in a subsequent study Dracatos et al. (2015) demonstrated that the Rpg5 locus also confers resistance to the heterologous oat-adapted f. sp. P. graminis f. sp. avenae. Kamino et al. (2015) mapped resistance to $P$. striiformis f. sp. pseudohordei on chromosome 1HS in two different barley DH mapping populations (Amaji Nijo/WI2585 and Galleon/Haruna Nijo). The colocation of the QTL identified in the P/B-19 mapping population in response to $P$. striiformis $\mathrm{f}$. $\mathrm{sp}$. tritici and $P$. striiformis $\mathrm{f}$. $\mathrm{sp}$. pseudo-hordei identified in the present study with previously mapped resistance to $P$. striiformis on chromosome 1HS suggests either the involvement of the same gene or a complex locus with tightlylinked genes that resides in the same region as the well documented Mla locus (Seeholzer et al. 2010).

Schulze-Lefert and Panstruga (2011) hypothesize that nonhost resistance may be based either on pathogen-associated molecular pattern-triggered immunity or on effective R-genes in the plant corresponding to cognate effectors in the nonadapted pathogen. As frequently observed in host pathogen interactions, isolatespecificity was also observed in barley in response to the diverse heterologous $P$. striiformis $\mathrm{f}$. sp. tritici isolates used in this study. Such isolate specificity of resistance to the different $P$. striiformis isolates (134 E16 A+, 104 E137 A-, and P. striiformis f. sp. pseudohordei) was best illustrated by histological studies. We compared the hyphal growth of both parents of the RIL population, RIL18 and wheat accession Avocet $S$ at 8 days after infection with all three isolates and observed a differential response in RIL18 (P. striiformis f. sp. pseudo-hordei susceptible, intermediate resistance to $P$. striiformis f. sp. tritici isolate $104 \mathrm{E} 137 \mathrm{~A}$ - and complete immunity to $P$. striiformis f. sp. tritici isolate $134 \mathrm{E} 16 \mathrm{~A}+$ ). Because the lines examined were not near-isogenic, the contribution of each QTL on the observed differential response could not be determined. Nonetheless, the histological analyses did indicate the presence of isolate-specific resistance in the P/B-19 mapping population. As such, RIL18 may be useful for distinguishing between $P$. striiformis isolates adapted to different grass host species. The selection of RILs based on closely linked marker alleles is likely to permit further Mendelisation of each QTL for future fine mapping and cloning efforts.

Various studies in wheat have established that some durable APR genes are pleiotropic, conferring resistance to more than one biotrophic pathogen (Herrera-Foessel et al. 2011; William et al. 2003). In the present study, only a single QTL (Rphql) for leaf rust resistance in the $\mathrm{P} / \mathrm{B}-19$ mapping population was mapped on chromosome 5HS, corresponding to Rph20. Contingency $\chi^{2}$ tests and imputing the mean disease ratings in the P/B-19 mapping population for lines either carrying or lacking the $b \mathrm{~Pb}$-0837 marker allele confirmed the lack of association of Rph20 with resistance to the $P$. striiformis isolates used in this study. We did, however, identify seedling-susceptible RILs to $P$. striiformis $\mathrm{f}$. sp. pseudohordei that were resistant in the field consistent with the presence of APR to P. striiformis f. sp. pseudo-hordei. This was further supported by the presence of a QTL on chromosome 7HS in both 2015 and 2016 field seasons that was not detected at the seedling stage. Singh et al. (2015) previously mapped a minor effect QTL to leaf rust in the Australian variety Yerong on 7HS which was formally designated as the APR locus Rph23. The peak LOD score for the 7HS QTL was located in the same region as the previously characterized leaf rust APR loci viz. Rph23 suggesting that either it is a closely linked gene or that $R p h 23$ may also confer resistance to $P$. striiformis f. sp. pseudo-hordei. Based on the lack of common markers between genetic maps and the absence of the Yerong Ebmac0603-resistance marker allele in either parent it is hard at this stage to speculate on the involvement of Rph23 in the APR to P. striiformis f. sp. pseudo-hordei identified on $7 \mathrm{HS}$ from Pompadour. Further studies investigating their genetic relationship are warranted given the importance of such gene associations in resistance breeding.

\section{ACKNOWLEDGMENTS}

We thank M. Williams for valuable technical assistance. We thank and acknowledge R. Singh and his team from CIMMYT for all their efforts in the phenotypic assessment of the P/B-19 mapping population with P. striiformis f. sp. hordei in Toluca, Mexico.

\section{LITERATURE CITED}

Atienza, S. G., Jafary, H., and Niks, R. E. 2004. Accumulation of genes for susceptibility to rust fungi for which barley is nearly a nonhost results in two barley lines with extreme multiple susceptibility. Planta 220:71-79.

Ayliffe, M., Devilla, R., Mago, R., White, R., Talbot, M., Pryor, A., and Leung, H. 2011. Nonhost resistance of rice to rust pathogens. Mol. Plant-Microbe Interact. 24:1143-1155.

Brueggeman, R., Rostoks, N., Kudrna, D., Kilian, A., Han, F., Chen, J., Druka, A., Steffenson, B., and Kleinhofs, A. 2002. The barley stem rust-resistance gene Rpg1 is a novel disease-resistance gene with homology to receptor kinases. Proc. Natl. Acad. Sci. USA 99:9328-9333.

Castro, A. J., Capettini, F., Corey, A., Filichkina, T., Hayes, P. M., Kleinhofs, A., Kudrna, D., Richardson, K., Sandoval-Islas, S., and Rossi, C. 2003. Mapping and pyramiding of qualitative and quantitative resistance to stripe rust in barley. Theor. Appl. Genet. 107:922-930.

Chen, X., and Line, R. 2002. Identification of genes for resistance to Puccinia striiformis f. sp. hordei in 18 barley genotypes. Euphytica 129:127-146.

Chen, X., Moore, M., Milus, E. A., Long, D. L., Line, R. F., Marshall, D., and Jackson, L. 2002. Wheat stripe rust epidemics and races of Puccinia striiformis f. sp. tritici in the United States in 2000. Plant Dis. 86:39-46.

Churchill, G. A., and Doerge, R. W. 1994. Empirical threshold values for quantitative trait mapping. Genetics 138:963-971.

Dawson, A. M., Ferguson, J. N., Gardiner, M., Green, P., Hubbard, A., and Moscou, M. J. 2016. Isolation and fine mapping of Rps6: An intermediate host resistance gene in barley to wheat stripe rust. Theor. Appl. Genet. 129: 831-843. 
Derevnina, L., Zhou, M., Singh, D., Wellings, C. R., and Park, R. F. 2015. The genetic basis of resistance to barley grass yellow rust (Puccinia striiformis f. sp. pseudo-hordei) in Australian barley cultivars. Theor. Appl. Genet. 128:187-197.

Doerge, R. W., and Churchill, G. A. 1996. Permutation tests for multiple loci affecting a quantitative character. Genetics 142:285-294.

Dracatos, P., Singh, D., Fetch, T., and Park, R. 2015. Resistance to Puccinia graminis f. sp. avenae in barley is associated with the Rpg5 locus. Phytopathology 105:490-494.

Dracatos, P. M., Ayliffe, M., Khatkar, M. S., Fetch, T., Singh, D., and Park, R. F. 2014. Inheritance of prehaustorial resistance to Puccinia graminis f. sp. avenae in barley (Hordeum vulgare L.). Mol. Plant-Microbe Interact. 27:1253-1262.

Eriksson, J. 1894. Ueber die specialisirung des parasitismus bei den getreiderostpilzen. Ber. Dtsch. Bot. Ges. 12:292-331.

Golegaonkar, P. G. 2007. Genetic and molecular analysis of resistance to rust diseases in barley. M.Sc. Thesis. University of Sydney, Plant Breeding Institute, Cobbitty, Australia.

Golegaonkar, P. G., Wellings, C. R., Singh, D., and Park, R. F. 2013. Genetic and molecular analyses of resistance to a variant of Puccinia striiformis in barley. J. Appl. Genet. 54:1-9.

Heath, M. C. 2000. Nonhost resistance and nonspecific plant defenses. Curr. Opin. Plant Biol. 3:315-319.

Heath, M. C. 2002. Cellular interactions between biotrophic fungal pathogens and host or nonhost plants. Can. J. Plant Pathol. 24:259-264.

Herrera-Foessel, S. A., Lagudah, E. S., Huerta-Espino, J., Hayden, M. J., Bariana, H. S., Singh, D., and Singh, R. P. 2011. New slow-rusting leaf rust and stripe rust resistance genes $\operatorname{Lr67}$ and $\mathrm{Yr} 46$ in wheat are pleiotropic or closely linked. Theor. Appl. Genet. 122:239-249.

Herrera-Foessel, S. A., Singh, R. P., Lan, C. X., Huerta-Espino, J., Calvo-Salazar, V., Bansal, U. K., Bariana, H. S., and Lagudah, E. S. 2014. Yr60, a gene conferring moderate resistance to stripe rust in wheat. Plant Dis. 99:508-511.

Hickey, L. T., Lawson, W., Platz, G. J., Dieters, M., Arief, V. N., Germán, S., Fletcher, S., Park, R. F., Singh, D., Pereyra, S., and Franckowiak, J. 2011. Mapping Rph20: A gene conferring adult plant resistance to Puccinia hordei in barley. Theor. Appl. Genet. 123:55-68.

Hickey, L. T., Lawson, W., Platz, G. J., Fowler, R. A., Arief, V., Dieters, M., Germán, S., Fletcher, S., Park, R. F., Singh, D., Pereyra, S., and Franckowiak, J. 2012. Mapping quantitative trait loci for partial resistance to powdery mildew in an Australian barley population. Crop Sci. 52: 1021-1032.

Jafary, H., Albertazzi, G., Marcel, T. C., and Niks, R. E. 2008. High diversity of genes for nonhost resistance of barley to heterologous rust fungi. Genetics 178:2327-2339.

Jafary, H., Szabo, L. J., and Niks, R. E. 2006. Innate nonhost immunity in barley to different heterologous rust fungi is controlled by sets of resistance genes with different and overlapping specificities. Mol. Plant-Microbe Interact. 19:1270-1279.

Kamino, L. N., Singh, D., Pallotta, M. A., Collins, N. C., and Park, R. F. 2015. Mapping of seedling resistance in barley to Puccinia striiformis f. sp. pseudo-hordei. J. Appl. Genet. 57:37-44.

Krattinger, S. G., Lagudah, E. S., Spielmeyer, W., Singh, R. P., Huerta-Espino, J., McFadden, H., Bossolini, E., Selter, L. L., and Keller, B. 2009. A putative $\mathrm{ABC}$ transporter confers durable resistance to multiple fungal pathogens in wheat. Science 323:1360-1363.

Li, K., Hegarty, J., Zhang, C., Wan, A., Wu, J., Guedira, G. B., Chen, X., Muñoz-Amatriaín, M., Fu, D., and Dubcovsky, J. 2016. Fine mapping of barley locus Rps6 conferring resistance to wheat stripe rust. Theor. Appl. Genet. 129:845-859.

Marcel, T. C., Varshney, R., Barbieri, M., Jafary, H., De Kock, M., Graner, A., and Niks, R. 2007. A high-density consensus map of barley to compare the distribution of QTLs for partial resistance to Puccinia hordei and of defence gene homologues. Theor. Appl. Genet. 114:487-500.

McIntosh, R. A., Wellings, C. R., and Park, R. F. 1995. Wheat Rusts: An Atlas of Resistance Genes. Csiro Publishing, Melbourne.

Moore, J. W., Herrera-Foessel, S., Lan, C., Schnippenkoetter, W., Ayliffe, M., Huerta-Espino, J., Lillemo, M., Viccars, L., Milne, R., Periyannan, S., Kong, X., Spielmeyer, W., Talbot, M., Bariana, H., Patrick, J. W., Dodds, P.,
Singh, R., and Lagudah, E. 2015. A recently evolved hexose transporter variant confers resistance to multiple pathogens in wheat. Nat. Genet. 47: 1494-1498.

Niks, R. E. 1986. Variation of mycelial morphology between species and formae spéciales of rust fungi of cereals and grasses. Can. J. Bot. 64: 2976-2983.

Niks, R. E., Alemu, S. K., Marcel, T. C., and van Heyzen, S. 2015. Mapping genes in barley for resistance to Puccinia coronata from couch grass and to P. striiformis from brome, wheat and barley. Euphytica 206:487-499.

Niks, R. E., and Marcel, T. C. 2009. Nonhost and basal resistance: How to explain specificity? New Phytol. 182:817-828.

Niks, R. E., van Heyzen, S., Szabo, L. J., and Alemu, S. K. 2013. Host status of barley to Puccinia coronata from couch grass and P. striiformis from wheat and brome. Eur. J. Plant Pathol. 136:393-405.

Pahalawatta, V., and Chen, X. 2005a. Genetic analysis and molecular mapping of wheat genes conferring resistance to the wheat stripe rust and barley stripe rust pathogens. Phytopathology 95:427-432.

Pahalawatta, V., and Chen, X. 2005b. Inheritance and molecular mapping of barley genes conferring resistance to wheat stripe rust. Phytopathology 95:884-889.

Peterson, R. F., Champbell, A. B., and Hannah, A. E. 1948. A diagrammatic scale for estimating rust intensity of leaves and stem of cereals. Can. J. Res. 26:496-500.

Randhawa, M., Bansal, U., Valarik, M., Klocova, B., Dolezel, J., and Bariana, H. 2014. Molecular mapping of stripe rust resistance gene $\operatorname{Yr} 51$ in chromosome 4AL of wheat. Theor. Appl. Genet. 127:317-324.

Schulze-Lefert, P., and Panstruga, R. 2011. A molecular evolutionary concept connecting nonhost resistance, pathogen host range, and pathogen speciation. Trends Plant Sci. 16:117-125.

Seeholzer, S., Tsuchimatsu, T., Jordan, T., Bieri, S., Pajonk, S., Yang, W., Jahoor, A., Shimizu, K. K., Keller, B., and Schulze-Lefert, P. 2010. Diversity at the Mla powdery mildew resistance locus from cultivated barley reveals sites of positive selection. Mol. Plant-Microbe Interact. 23:497-509.

Singh, D., Dracatos, P., Derevnina, L., Zhou, M., and Park, R. F. 2015. Rph23: A new designated additive adult plant resistance gene to leaf rust in barley on chromosome 7H. Plant Breed. 134:62-69.

Sui, X., He, Z., Lu, Y., Wang, Z., and Xia, X. 2010. Molecular mapping of a non-host resistance gene YrpstY1 in barley (Hordeum vulgare L.) for resistance to wheat stripe rust. Hereditas 147:176-182.

Wang, X., Richards, J., Gross, T., Druka, A., Kleinhofs, A., Steffenson, B., Acevedo, M., and Brueggeman, R. 2013. The rpg4-mediated resistance to wheat stem rust (Puccinia graminis) in barley (Hordeum vulgare) requires Rpg5, a second NBS-LRR gene, and an actin depolymerization factor. Mol. Plant-Microbe Interact. 26:407-418.

Wellings, C. R. 2007. Puccinia striiformis in Australia: A review of the incursion, evolution, and adaptation of stripe rust in the period 1979-2006. Aust. J. Agric. Res. 58:567-575.

Wellings, C. R., Burdon, J. J., McIntosh, R. A., Wallwork, H., Raman, H., and Murray, G. M. 2000. A new variant of Puccinia striiformis causing stripe rust on barley and wild Hordeum species in Australia. Plant Pathol. 49:803.

Wellings, C. R., Wright, D. G., Keiper, F., and Loughman, R. 2003. First detection of wheat stripe rust in Western Australia: Evidence for a foreign incursion. Australas. Plant Pathol. 32:321-322.

William, M., Singh, R. P., Huerta-Espino, J., Islas, S. O., and Hoisington, D. 2003. Molecular marker mapping of leaf rust resistance gene $\operatorname{Lr} 46$ and its association with stripe rust resistance gene $\mathrm{Yr} 29$ in wheat. Phytopathology 93:153-159

Yeo, F. K. S., Wang, Y., Vozabova, T., Huneau, C., Leroy, P., Chalhoub, B., Qi, X. Q., Niks, R. E., and Marcel, T. C. 2015. Haplotype divergence and multiple candidate genes at Rphq2, a partial resistance QTL of barley to Puccinia hordei. Theor. Appl. Genet. 129:289-304.

Zhou, M., and Li, H. 2008. Identification of molecular markers associated with powdery mildew and barley grass stripe rust resistance. Pages 381-384 in: Proceedings of the 10th International Barley Genetics Symposium, Alexandria, Egypt.

Ziems, L. A., Hickey, L. T., Platz, G. J., Franckowiak, J. D., Dracatos, P. M., Singh, D., and Park, R. F. 2017. Characterization of Rph24: A gene conferring adult plant resistance to Puccinia hordei in barley. Phytopathology 107:834-841. 